\title{
Social Capital and Knowledge Transfer in New Service Development: The Front/Back Office Perspective
}

\author{
Jing-Hua Li, Qiu-Bo Huang, and Li Lin \\ Research Centre for Technology Innovation and Service \\ Management, School of Business Administration, \\ Zhejiang Gongshang University, Hangzhou, China
}

\section{ihli@mail.zigsu.edu.cn hqb919@163.com kantarlily@126.com}

\begin{abstract}
The linkage of front and back office operations significantly influences the performance of new service development. Through a multi-case study of four regional banks in China, we explored the influencing mechanisms relating to knowledge transfer between front office and back office in new service development. We confirmed that the structural dimension of social capital (tie strength) strongly influences knowledge transfer performance through knowledge transfer opportunity, the cognitive dimension (common cognition) influences knowledge transfer through transfer capability, and the relational dimension (trust relation) exerts its influence through transfer willingness. Structural and relational social capital each has significant influence on knowledge transfer, which supports the view of the organizational system school in services. This study indicates that a service firm should build and utilize both "hard" and "soft" social capital simultaneously, so it is important to recognize customers' needs based on daily interaction through knowledge transfer from the front office.
\end{abstract}

Keywords: knowledge transfer; social capital; front/back office; new service development; case study; banking; China

\section{Introduction}

In most major developed countries, the added value of services accounts for over $70 \%$ of the GDP (in 2012, the percentages for the U.S.A, France and Germany are respectively $79.7 \%$, $79.8 \%$ and $71.1 \%$ ), while China is lagging behind with a rate of only $44.6 \%$ in 2012 . The development of China's services must rely on the proliferation of service innovation on a wide scale. This effort will involve identifying customer's needs, introducing new services, and improving

Material published as part of this publication, either on-line or in print, is copyrighted by the Informing Science Institute. Permission to make digital or paper copy of part or all of these works for personal or classroom use is granted without fee provided that the copies are not made or distributed for profit or commercial advantage AND that copies 1) bear this notice in full and 2) give the full citation on the first page. It is permissible to abstract these works so long as credit is given. To copy in all other cases or to republish or to post on a server or to redistribute to lists requires specific permission and payment of a fee. Contact Publisher@,InformingScience.org to request redistribution permission. management models. The success of new service development (NSD) is affected by the organization and structure of service enterprises. One of the primary determining factors is knowledge transfer between front office and back offices.

The separation of front and back offices makes it difficult for the offices to sympathize with each other in NSD. There 
exist significant differences between the front and back offices with regards to labor intensity, personnel quality, task focus, and other areas that result in a knowledge gap. It can be difficult for front office staff to translate valuable experience into effective input required for NSD. Without this input it is difficult to properly develop new services that meet customer needs.

Studies show that, although the essence of innovation is knowledge creation (Shu, 2007), knowledge transfer plays a significant role in innovation performance (Sarin \& Mcdermott, 2003). Tao, Wei, and Wang (2007) divide the financial innovation process into several stages from the perspective of knowledge transfer. This provides for the analysis of the level of influence of organizational structure on knowledge transfer in financial enterprises. Additional studies have shown that while social capital plays a critical part in knowledge transfer, front/back office interaction in service organizations introduces complex influences on the knowledge transfer process in NSD.

This paper conducts a multi-case study on regional banking institutions designed to explore the following two questions: (1) what is the state of front/back office linkage in NSD, and (2) how do organizational contacts between front and back offices influence knowledge transfer in NSD?

\section{Literature and Framework}

\section{New Service Development}

In the late 1980s the concept of new service development (NSD) was described based on the study of new product development, which defines NSD as the process of developing a new service product by the service provider (Johne \& Storey, 1998). In addition, Menor and Roth (2008) believe that NSD is not simply the development of the new service product but also the development of the offerings of such services. Depending on the purpose for the development, NSD can be further divided into two categories (Johne, 1996). The first category focuses on reducing cost and is referred to as "new process development." The second category involves repositioning and is defined as "product diversification development." The task goals for both categories include the innovation of major service operations, the launch of new services, the offering of new services to existing markets, the extension of service lines, and the improvement and transformation of existing services (Lovelock, 1984). NSD implements structured phases such as the introduction and analysis of new concepts, the development and testing of the prototype service, and the launch of the new service (Voss, 1992). NSD defines the innovative activities that can be used by service providers in order to meet customers' demand.

\section{Front/back Service Office: the R\&D Perspective}

Front/back office is a term used to describe the business structure of a service operation. The front office provides services to clients and involves direct customer contact and services based on experience and knowledge, while the back office provides remote, behind-the-scene support and services (Johnston \& Clark, 2001). The back office assists the front office in providing more effective services (Metters \& Vargas, 2000). The front office is more labor-intensive while the back office is more capital-intensive (Safizadeh, Field, \& Ritzman, 2003). The types of tasks that the front office deals with can be varied and complex, while back office tasks are often distinct and well-defined (Boyer \& Lewis, 2002). There are clear definitions of the interaction between the front office and the customers as well as the interaction between the front office and back office (Larsson \& Bowen, 1989).

The organizational modes involved with service innovation are diversified. Based on the formality of R\&D activities and breadth and depth of participation within the enterprise, the organizational modes for service innovation can be divided into the following categories: the industrial 
R\&D mode led by the R\&D department, the professional service mode led by the business department, the organized strategic innovation mode led by the operations and managerial departments, the "craftsman" mode led by the staff members, and the network mode dominated by core enterprises, etc. (Gallouj \& Weinstein, 1997). Different projects require different organizational modes for innovation.

This study suggests that focusing on the basic common characteristics of service enterprises is more effective than trying to account for the diversity. In the concept generation stage of R\&D, the front office suggests a new service concept. In the development stage, the front and back offices cooperate to transform the market knowledge into product and technical specifications. In the introduction stage, staff in the front office promotes the new service to the market. The organizational context of front/back office is applied to the generic research for NSD.

\section{The General Framework for Knowledge Transfer}

Knowledge transfer is the cognitive process where the knowledge recipient acquires the same knowledge as the knowledge source and internalizes the knowledge to form his/her new knowledge (Krogh \& Roos, 1996). The basic framework required to analyze knowledge transfer within an organization involves three areas of interest: the knowledge characteristics, the activities of knowledge transfer, and the actual transfer performance (Cummings \& Teng, 2003).

Knowledge characteristics include knowledge articulability (Bou-Llusar \& Segarra-Ciprés, 2006), embeddedness (Argote \& Ingram, 2000), the observability of the role of knowledge (Galbraith, 1990), tacitness and explicitness (Reagans \& McEvily, 2003), etc. The characteristics of knowledge transfer activities include the characteristics of the subjects, such as credibility (Szulanski, 1996), motivating factors (Tang \& Shi, 2006), communication and coding skills (Berman \& Heilweg, 1989), transfer capability (Cohen \& Levinthal, 1998), transfer opportunity (Yi, 2006) and transfer willingness (Gupta \& Govindarajan, 2000), as well as situational factors, such as relationship quality (Szulanski, 1996), common understanding (Nelson \& Cooprider, 1996), organizational distance (Darr \& Kurtxberg, 2000), physical distance (Davenport \& Prusak, 1998), knowledge distance (Ma, Zhong, \& Chen, 2007), institutional distance (Kostova, 1999), and cultural distance (O'Dell \& Grayson, 1998). Knowledge transfer performance includes such aspects as knowledge sharing (Tsai, 2002), knowledge flow (Gupta \& Govindarajan, 2000), and new knowledge acquisition (Darr, Argote, \& Epple, 1995).

Based on these premises, the influencing factors on knowledge transfer include structural factors of front/back office, such as organizational structure and organizational distance, cognitive factors such as common understanding, knowledge distance, and knowledge sharing, and factors in the relational dimension, such as relationship quality and credibility. This is similar to the basic analytical framework of the Social Capital Theory, which is also applicable in the analysis of organizational knowledge transfer.

\section{The Connotation and Measurement of Social Capital of Front/back Office}

Social capital is the sum of the actual and potential resources embedded within, available through, and derived from the networks of relationships by an individual or a social unit (Lin, 2002). Social capital can exert an impact on the economic and social behaviors of its owner ( $\mathrm{Lu}, 2007)$. A major focus of this paper is to ascertain the influence of social capital status of front/back office on the behaviors in new service developing activities. The social capital status of front/back office can be assessed and described through observable variables. The measurement of social capital can be divided into individual measurement and collective measurement. 
Individual measurement describes individual social capital and focuses on the network measurement, such as network size, network components, and network density (de Silva, Huttly, Harpham, \& Kenward, 2006; Harpham. Grant, \& Thomas, 2002; Lochner, Kawachi, \& Kennedy, 1999). Individual location in the network as well as the resources embedded in the network should be alternative indicators in measurement (Bian, 1997; Lin, 2002). Collective measurement is used to describe the team. The social capital of an organization can usually be divided into several basic dimensions, namely, trust, public participation and social interaction ties, and social network structure and social norms. Based on different measuring dimensions, both singledimensional measurement and multi-dimensional measurements can be made on social capital attributes. Social capital is mostly manifested using tie strength in single-dimensional measurement (Granovetter, 1973), though trust is also used as a variable in some cases (Leana \& van Buren, 1999).

This study focuses at a level that falls between the organizational level and team level and addresses the influence that front/back office structure exerts on knowledge transfer. The relationship quality between the front and back office staff and the level of common cognition on the organizational level are also strong influences. In order to track and analyze all relevant data, this study adopts the widely accepted 3-dimension (structural, cognitive, and relational) framework of Nallapiet and Ghoshal (1998) to portray the social capital in the front/back office.

\section{Analysis Framework}

Existing research shows that network-level relational capital and cognitive capital have a great impact on knowledge transfer (Hansen, 1999). Structural factors such as the characteristics of network structure also have a significant influence on knowledge transfer (van Wijk, Jansen, \& Lyles, 2008). Based on this literature review, a theoretical framework is proposed as is shown in Figure 1.

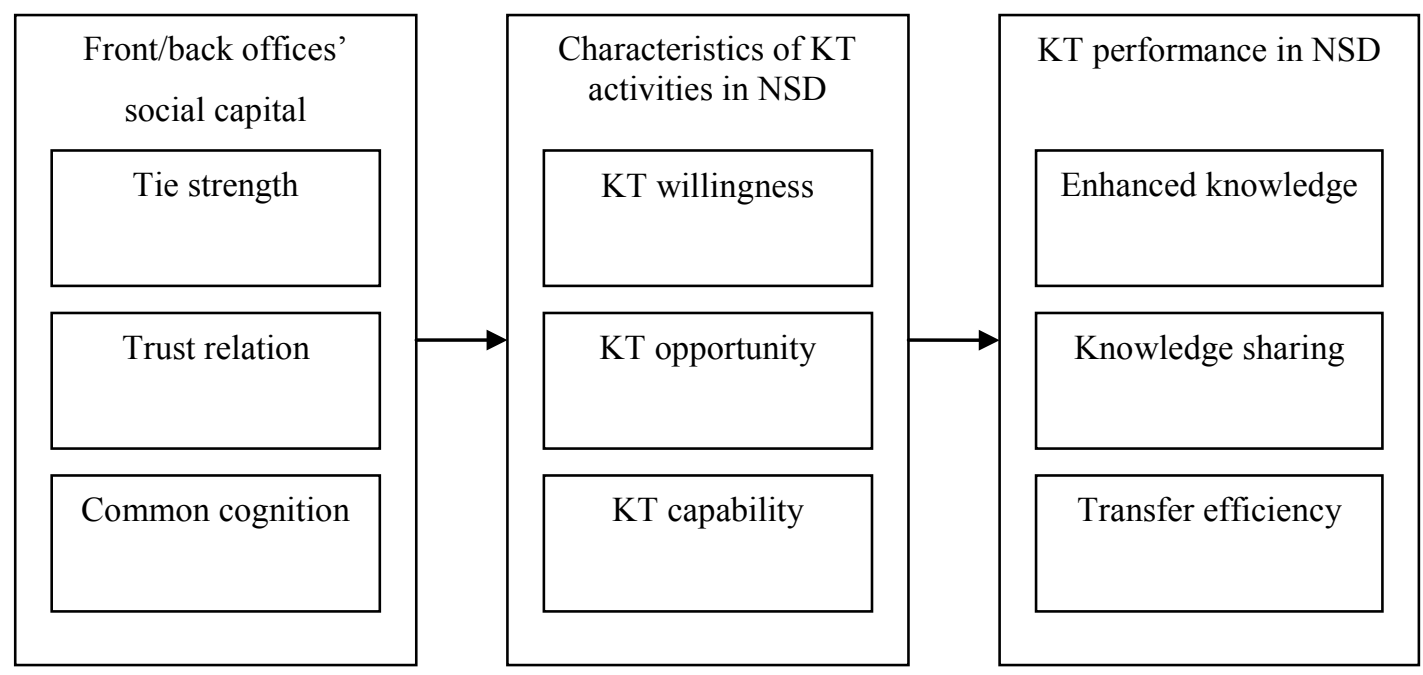

Figure 1. Theoretical framework 


\section{Methodology}

\section{Case and Project Selection}

This study chooses a multi-case research method. Case study methods are often used to solve complex questions that may not have definite answers and are suitable when constructing new theories or initiating preliminary analysis on new issues before further empirical testing. Although there are numerous research results that we can draw on as regard to the influence of social capital on knowledge transfer, the scenarios of NSD at different stages and for different projects are relatively complex, so methods and results from previous studies do not satisfy our research goals. A multi-case research design can help to compensate for the deficiency caused by inadequate coordination or incomplete cognition of the research objects in the data collection process (Yin, 2003).

Taking into account factors such as data accessibility, case typicality, and research convenience (Yan \& Gray, 1994), this paper selected several regional banks in Zhejiang Province of China as case subjects. The financial market in Zhejiang Province is among the most developed markets in China, incorporating 11 urban commercial banks (as of 2012, there are 144 urban commercial banks nationwide) and one rural commercial bank (consisting of 81 branches). These regional banks have a flat hierarchy and most of them have autonomous back-office systems, so they are more flexible in NSD compared with national commercial banks. These regional banks invest heavily in NSD to meet the diverse customer need to bank services, which results in a steady emergence of new service products. The banking industry is a typical industry in which front and back office structures are developed, though their front office is often better developed. Our researchers are all in Zhejiang Province and have extensive contacts with local banks, which greatly facilitated our research activities. Compared with other industries with front and back office structures such as the insurance industry, the banking industry has a more open attitude toward researchers.

We studied four regional banks, including two urban commercial banks and two rural commercial banks in Zhejiang Province of China (See Table 1 at end of paper). Of these banks, Bank of Hangzhou and Hangzhou United Bank are located in Hangzhou, the capital of Zhejiang Province, while Zhejiang Tailong Commercial Bank and Bank of Ruifeng are located, respectively, in Taizhou (the sixth most commercially active region) and Shaoxing (the third most commercially active region) in Zhejiang Province. The former two banks are larger than the latter two banks.

Then, we selected four NSD projects in the four banks, respectively (see Table 1 also). The first is the project of "Energy Management Contract Loan" in Bank of Hangzhou. Energy management firms--mostly SMEs--providing energy saving services to traditional organizations usually lack the capital to finance large energy-saving equipment and to implement technological innovation. In order to support these firms, an innovative loan product named the "Energy Management Contract Loan" was developed by Bank of Hangzhou with mortgage on the future income of energy management services.

The second is the project of "Entrepreneurship Loan" in Zhejiang Tailong Commercial Bank. The hardship that SMEs go through in applying conventional banking loans (with higher mortgage criteria and long processing period) and the emergence of "underground loan services" (with high interest rate and little legal protection) triggered the introduction of the loan product named "Entrepreneurship Loan" by Zhejiang Tailong Commercial Bank in 2007. The bank evaluates the financial and credit status of SMEs simply based on their utility bills and orders placed by their customers and provides loan services with low credit threshold and no handling charge while guarantees fast processing and no mortgage requirement with flexible channels to repay. 
The third project is the online banking service in Bank of Ruifeng. In 2007, online banking service was introduced by Zhejiang Credit Union (the parent organization of all rural banks in Zhejiang Province) to support the operation of rural banks. Bank of Ruifeng adopted the online service system in 2012 and accomplished a major leap in the infrastructure of its service offering.

The last project is the "Gold Consignment Service" in Hangzhou United Bank. In 2008, collaborating with Shanghai Gold Exchange, Hangzhou United Bank developed the intermediate service to answer to the demand of investment for customers across all branches in the county supported by advanced IT infrastructure.

\section{Data Collection and Coding}

We conducted seven semi-structured interviews with informants from several regional banks (both urban commercial banks and rural commercial banks) in Zhejiang Province of China from 2010 to 2012. Prior to our visits, an outline was sent to each corresponding bank to ensure the right informants were chosen and proper preparation done. Throughout each interview, notes were taken and the conversation was recorded. The average length of an interview is about 120 minutes. Following what Eisenhardt (1989) suggested, we conducted collation and reconciliation based on the notes taken and materials recorded within 24 hours after the interview; a contact memo was filled out for each interview and follow-up calls were made to confirm or obtain certain missing information.

This paper adopts the method of content-analysis. Assisted by the qualitative analysis tool QSR Nvivo 7.0, we first classified the documents from the interviews and established a project-level database of cases; next, aiming to achieve the plumpness of information, appropriate projects were screened out of the 20 projects investigated in the 10 interviews; finally, content-analysis (coding) was carried out one project after another.

The coding process includes the following steps. The first step is the open coding step based on the two-dimensional code dictionary established upon the development stage. At this step, preliminary coding was first accomplished, sentence by sentence, based on the material obtained from the interview, and keywords in each statement were identified as nodes; we established a firstlevel code dictionary consisting of 368 nodes. Then, we classified these 368 first-level nodes according to different stages, namely, concept generation stage, concept development stage, development stage, and introduction stage, and formed a two-dimensional code dictionary consisting of these four categories. The second step involved axial coding when all the open nodes in the twodimensional code library were coded into axial codes individually. Axial coding started with two members working separately before they sat together and compared their coding results. If the results were the same, then the coding was confirmed; if not, they needed to discuss and decide on a more accurate version or the deletion of certain results. After this step, 30 nodes were excluded and we finalized with 338 nodes. Examples of both open coding and axial coding are shown in Table 2 (at end of paper).

\section{Case Classification}

Eisenhardt (1989) argued that utilization of the case study method is susceptible to the influence of data vividness or more outstanding respondents, which makes it easy to ignore the basic statistical features. He proposed three types of multi-case study methods and this paper adopted the first method, which is identifying several categories or dimensions and finding similarities within the group and differences among groups. We also learnt from Miles et al.'s (1995) view and categorized the four project cases into two types based on the content of NSD: business innovation and process innovation. Each group contains two project-level cases and each project was labeled with an English letter for the convenience of the subsequent citation. 
The first type of cases is the business innovation project. The essence for business innovation projects is to discover potential customer demand and develop new service that is supplementary to conventional services.

At the concept generation stage, since the customers are seldom capable of articulating their potential demands as banking needs, it is essential for staff in the front office to keep close contact with their clients. The strong tie established by the front office staff with their clients can increase the opportunity for knowledge transfer; in addition, the high-level cognition and mutual trust between staff members in the front office as well as between front office and clients can enhance the willingness to transfer knowledge; meanwhile, common understanding of the regional market can promote the capability of mutual understanding. The performance of knowledge transfer at this stage is manifested by the acquisition and internalization of tacit knowledge and the expression of possible new service concepts, i.e., the increase of enhanced knowledge.

At the concept development stage, strong tie is formed between staff in front and back offices; there is higher level of trust relation and common cognition, more knowledge transfer opportunities, stronger transfer willingness and capability, higher level of knowledge sharing, more significant increase in enhanced knowledge, and higher transfer efficiency. In addition, equal attention was paid to the transfer of both tacit and explicit knowledge.

At the development stage, there are relatively weaker ties between front office and risk management, legal and accounting departments; there are just moderate level of trust relation and transfer willingness between the front and back offices. However, the level of communication and sharing between the front and back offices is high which leads to relatively high level of expressive and absorptive capability. As for the customers, there is no similar existing service to refer to as regard to the brand-new service; led by the front office, product introduction is extensively carried out together with the back office.

So at the introduction stage, there are constant contacts between the front and back offices leading to more transfer opportunities; nevertheless, due to the existence of market distance, back office lacks the business knowledge at this stage, so it merely plays a complementary role for the front office which leads to medium level of trust relation and cognition between front and back offices, as well as medium level of transfer capability and willingness. So tacit knowledge, such as knowledge relating to products and markets, is shared at this stage, while there is only a limited space to improve both in enhanced knowledge and transfer efficiency.

The second type of case is the process innovation project. The goal for process innovation projects is mainly to improve business operation through intensive modification of the existing information system (e.g., by building online banking platforms). This type of project usually acquires a relatively specific product concept (explicit knowledge) through the weak tie between front office and clients or among colleagues, and medium-level trust relation and cognitive relations; knowledge sharing is then realized. Due to the relatively strict requirement on the system, a strong tie is usually needed between the front and back offices at the concept development and development stages so that high-level trust relation and cognition can promote greater transfer willingness between the front and back offices, and more transfer opportunities and greater transfer capabilities make it possible for the integration of the first line experience (tacit knowledge) of the front office staff and the expertise of the back office staff (explicit knowledge). Knowledge transfer performance is significant at this stage. The great involvement of front office staff at the development stage relieved, to a certain extent, the pressure of imparting product knowledge from the back to the front office at the introduction stage. Thus, at the introduction stage, there is only weak tie between the front and back offices with medium level of trust relation, common cognition and transfer willingness, and lower level of transfer capability. Sometimes, trainings should 
be carried out in order to compensate for this weak point. This stage mainly realizes the sharing of product- and operation-related knowledge.

\section{Findings}

\section{Propositions}

Coding results of the characteristics of back-office ties and knowledge transfer for the two types of projects are summarized in Table 3 (at end of paper). By comparing the levels of strength among different constructs in the coding results of the two types of innovation projects in Table 4 (at end of paper), plus the cited sentences in the respondents' interview and supporting literatures, we can determine the basic influence direction among the constructs.

There are always some difficulties in applying the grounded theory method in case studies when we try to determine the levels of relationship strength among different constructs. Typical citation of the respondents' words can only prove the existence of relationships but cannot indicate the levels of strength in relationships. In this paper, we make some improvements on the rules proposed by $\mathrm{Yao}, \mathrm{Hu}$, and $\mathrm{Ye}(2012)$ regarding the way to distinguish tie strengths and propose that when the ratio of the number of items representing certain relationship to the total item numbers in the same relationship group is no less than the average ratio (i.e., the reciprocal of the number of relationship groups), the relationship is strong. The matrix query function of the Nvivo content analysis software can help us get the total number of the same items among different nodes and the corresponding ratios. On this basis, we test the causal logics among the coding results in different items and exclude the items without significant causal relationship and finally get a more objective judgment on the relationship strength with significant causal relations.

From the coding results of the two types of innovation projects in Table 3 (at end of paper), we can see that when there is strong tie strength, there are more transfer opportunities, stronger transfer capability, and stronger transfer willingness; and when the tie strength is weak, there are less transfer opportunities, medium-level transfer capability, and medium-level transfer willingness. The occurrence of exceptional cases is due to the heterogeneities of influence relationships existing among different constructs; this will be explained in the discussion part of this paper. The general relationships listed above can be proven by the specific statements of the respondents (see Table 4 ).

In addition, the research on R\&D activities in medical and health services also shows that knowledge transfer can be facilitated through enhancing contacts (Hammami, Amara, \& Landry, 2013), and there is a positive influence of the team-level structural dimension of social capital on transfer opportunity (Li \& Zhu, 2009). S. Kim, Suh, and Jun (2011) also emphasized that adding a middleman plays the role to pull the two sides in the knowledge transfer network together, thus creating more knowledge transfer opportunities. Furthermore, due to the diversity of transfer channels, both parties can choose the channel that is most conductive to mutual understanding to accomplish the knowledge transfer (Zhu, 2010). Thus, the proposition is:

Proposition 1: There is a strong positive influence of front/back office tie strength on knowledge transfer opportunity.

In Table 3, we can see that when there is high level of trust relation between front and back offices, there are more transfer opportunities, stronger transfer capability, and stronger transfer willingness; and when the trust relation level is medium, there are less transfer opportunities, medium-level transfer capability, and medium-level transfer willingness. The persons interviewed also have clear statements of such trends as mentioned above (see Table 4 also). In addition, similar studies also confirm that active inter-department relations can promote initiative of knowledge 
exchange and thus increase the effectiveness of knowledge transfer (Karlsen \& Gottschalk, 2004); on the contrary, inter-department conflicts will hamper the knowledge sharing willingness (Y. Kim, Lee, \& Gosain, 2005), and the trust relation has positive influence on transfer willingness (Li \& Zhu, 2009). Thus, the proposition is:

\section{Proposition 2: There is a strong positive influence of front/back office trust relation on} knowledge transfer willingness.

In Table 3, we can see that when there is high level of common cognition between front and back offices, there are more transfer opportunities, stronger transfer capability, and stronger transfer willingness; when the common cognition level is relatively low, there are less transfer opportunities, medium-level transfer capability, and medium-level transfer willingness. The persons interviewed also have clear statements in this aspect (see Table 4 also). In addition, the study on the knowledge transfer in project teams also found that common cognition of a moderate degree can enhance the favorable feelings among parties in knowledge transfer (Bakker, Cambr, Korlaar, \& Raab, 2011). The study on knowledge transfer in international cooperative organizations suggests that such factors as cooperation experience and similar knowledge background are conductive to the promotion of common understanding (Park, 2011). Thus, the propositions are:

Proposition 3: There is a strong positive influence of front/back office common cognition on transfer willingness.

Proposition 4: There is a strong positive influence of front/back office common cognition on transfer capability.

Coding results of the characteristics of back-office ties and knowledge transfer for the two types of projects (Table 3) also indicated that when there is strong willingness in front/back office knowledge transfer there will be a more significant increase in enhanced knowledge, a higher level of knowledge sharing, and transfer efficiency. For example, we can see this at the concept generation, concept development, and development stages of business innovation projects, and at the concept generation and development stages of process innovation projects. When there is only medium-level willingness in front/back office knowledge transfer, the increase in enhanced knowledge will be less significant along with lower level of transfer efficiency. This can be seen at the introduction stage of business innovation projects, at the concept generation and introduction stages of process innovation projects. Aalbers, Dolfsma, and Koppius (2013) studied the individual innovation network and proposed that the internal motivation of individuals is the key factor to promote knowledge transfer. Our respondents also have clear statements regarding this (see Table 5 at end of paper). Thus, the propositions are:

Proposition 5: There is a strong positive influence of front/back office knowledge transfer willingness on the enhanced knowledge.

Proposition 6: There is a strong positive influence of front/back office knowledge transfer willingness on knowledge sharing.

In Table 3, we can see that, in general, when there are more knowledge transfer opportunities between front and back offices, there is a significant increase in enhanced knowledge with apparent improvement in knowledge sharing and transfer efficiency. This, for example, will occur at the concept generation, concept development, and introduction stages of business innovation projects, and at concept development and development stages of process innovation projects. When there are only a few opportunities for knowledge transfer, the increase in enhanced knowledge will not be high, both the level of sharing and the transfer efficiency are relatively low. This, for example, will occur at the development stage of business innovation projects and concept generation and introduction stages of process innovation projects. Studies on the internal communication of cross-functional teams did show that diversity of communication channels and abundance 
of communication time will promote group cooperation and sharing (Park, 2011). Our respondents also have clear statements in this aspect (see Table 5 also). Thus, the propositions are:

Proposition 7: There is a strong positive influence of front/back office knowledge transfer opportunity on knowledge sharing.

Proposition 8: There is a strong positive influence of front/back office knowledge transfer opportunity on knowledge transfer efficiency.

In Table 3, we can see that, in general, when there is stronger capability in front/back office knowledge transfer, there will be a more significant increase in enhanced knowledge as well as a higher level of knowledge sharing and transfer efficiency. When there is weak capability in front/back office knowledge transfer, the increase in enhanced knowledge will be less significant along with lower level of knowledge sharing and transfer efficiency. The knowledge absorptive capacity of the knowledge recipient exerts a positive effect on the knowledge transfer performance through his/her contextual adaptability in knowledge transfer (R. Zhang \& Yu, 2008). Our respondents also have clear statements regarding this (see Table 5 also). Thus, the propositions are:

Proposition 9: There is a strong positive influence of front/back office knowledge transfer capability on knowledge sharing.

Proposition 10: There is a strong positive influence of front/back office knowledge transfer capability on knowledge transfer efficiency.

\section{Result Model}

Based on the above propositions, we can get the conceptual model of the influence mechanism of social capital of front/back office on the effect of knowledge transfer (see Figure 2). We confirmed that the structural dimension of social capital (tie strength) exerts its influence on knowledge transfer performance through knowledge transfer opportunity, while the cognitive dimension (common cognition) influences through transfer capability and willingness, and the relational dimension (trust relation) exerts its influence through transfer willingness.

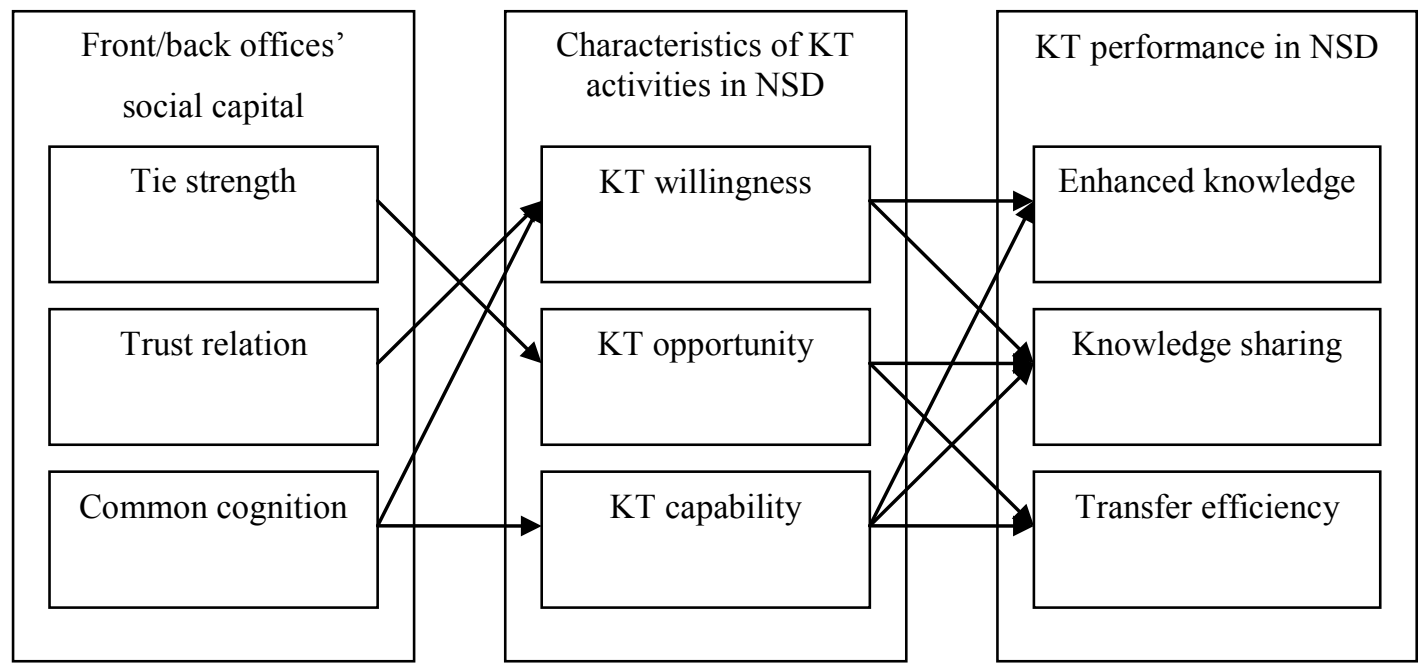

Figure 2 Result model 


\section{Discussion}

\section{The Influence of Social Capital on the Characteristics of Knowledge Transfer Activities}

As to the influence of social capital on front/back office on the characteristics of knowledge transfer activities, first of all, there is a relatively strong influence of front/back office tie strength on the knowledge transfer opportunity. This is very similar to G. Zhang, Liu, and Shen's (2011) view that organizational structure exerts significant influence on the internal knowledge transfer opportunity within an organization through numerous knowledge transfer channels and the network effect in the organization. With strong tie, there will be more frequent interactions, which lead to significantly more opportunities for front/back office contacts to understand specific knowledge. It is easy for front/back office, with strong tie, to acquire each other's information of multi-dimension, which has, to some extent, promoted mutual understanding. In addition, when there are diverse channels for knowledge transfer, staff from both the front and back offices would not consider it troublesome to deliver information, which has also, to some degree, enhanced knowledge transfer willingness.

Second, trust relation has a relatively strong influence on transfer willingness. So it can be implied that trust relation mainly exerts its influence on knowledge transfer through emotional factors (Ke \& Shi, 2007). Research has found that there are two sources of trust: one is a more subjective emotional trust established due to good interpersonal relationships among front/back office staff; the other one is more objective which is formed because of the faith in the counterpart's work competence. In addition, there are also two sources of transfer willingness: one is more active since it comes from the initiative to be recognized and to fulfill oneself; the other is more passive because it comes from such organizational stress as evaluation and moral pressure. This paper indicates that trust relation in NSD mainly exerts its impact through influencing the subjective feelings of the front/back office staff so to promote active participation in knowledge transfer activities. This conforms to the scenario of NSD in which, due to rigid constraints, NSD in banks has much lower level of tolerance to the degree of innovation compared with the situation with new product innovation; this is because NSD in banks has weaker reliance on individual technique capability as does in new product development; NSD relies more on group collaboration, so the major factor in trust relation is emotional trust rather than trust in people's competence. Due to emotional trust, parties in knowledge transfer will have little concern over the exposure of one's own flaws or mistakes, which will in turn enhance their expectation of the acceptance of their ideas and the awards thus received from the organization. Therefore, trust plays a great role in promoting transfer willingness when there is separation between front and back offices.

Finally, the common cognition of front/back offices has a strong influence on transfer willingness and capability. The common cognition of front/back offices in NSD includes the acceptance of organizational culture and values, the active understanding of the importance of the new service developing work, and the schedule control and evaluation on the developing work. The common cognition in organizational culture and values enhances the initiative in front/back office knowledge transfer, and this is very similar to Francis Fukuyama's view that common cognition such as values facilitates resource exchange. On the other hand, as the staff at Zhejiang Tailong Commercial Bank has put it, "We need to be put in an open environment since the participation in knowledge transfer in a closed environment will produce much pressure." However, firms usually exert "performance pressure" on planning and schedule control of NSD, therefore, staff has no choice but to participate in knowledge transfer, even with reluctance. So we can see that common cognition influences transfer willingness in both active and passive ways. Meanwhile, shared language, cooperative experience, structured knowledge, and component knowledge in common cognition are the foundation of mutual understanding between front and back offices. Knowledge 
distance brought about by job content differences between front and back offices can be shortened through training, enhanced communication, and rotation, so that mutual understanding is greatly elevated through the establishment of shared language and the improvement of structured knowledge (Ghobadi \& D'Ambra, 2011). We have found that banks excelling in NSD have invested heavily in this aspect.

\section{The Influence of the Characteristics of Knowledge Transfer Activities on the Transfer Performance}

As to the influence of the characteristics of knowledge transfer activities on the transfer performance, first, knowledge transfer willingness has a significant influence on enhanced knowledge and knowledge sharing. The willingness to transfer knowledge influences all sorts of knowledge sharing processes and the further processing of the shared knowledge into new one. The willingness also can lower the degree of concern over risks and costs thus making the communication within an organization smoother (Zhu, 2010). It seems non-realistic that there is only weak association between transfer willingness and efficiency; because judging from common sense, we usually hold that if there is a high level of transfer willingness, the transferring party will intend to deliver the knowledge immediately while reducing any chances of stagnation. That is to say, higher willingness brings higher efficiency. By looking back on the total item numbers and proportions regarding knowledge transfer willingness and transfer efficiency $(9.7 \%)$, we can see that this number is very close to the critical point between "strong" and "weak"; so we may tell that this may be caused by the misjudgment due to inaccuracy in the content analysis.

Second, transfer capability has strong influence on transfer efficiency, as well as on level of sharing and enhanced knowledge. The better knowledge expressive and absorptive capability between the front and back offices, the faster the knowledge transfer will be, so that the market knowledge accumulated at the front office can be transformed into comprehensible technical or legal knowledge at the back office with a higher speed. Also, the tacit knowledge gathered from both the front and back offices can be organized and processed into new knowledge. Finally, transfer opportunity has a significant influence on the level of knowledge sharing and communication efficiency. According to Nonaka and Takeuchi (1995), knowledge sharing is a critical condition for the generation of new knowledge; however, with the distinction in individual behaviors and competence, and various goals to achieve, knowledge sharing will not necessarily lead to the generation of new knowledge.

\section{Conclusions and Prospects}

\section{Conclusions}

By conducting a multi-case study on regional banks in China, this paper analyses the knowledge transfer mechanism of NSD in the context of front/back office organizational structure in service organizations. From different levels of innovation, we identified two types of projects in NSD in banks, and revealed, based on the four stages of NSD for different projects, major focuses of knowledge transfer activities as well as the differences existing in social capital at front and back offices. Of the two types of projects, knowledge transfer mainly happens at the concept generation and development stages of business innovation projects and at the development stages of process innovation projects; both types of innovation projects have high general requirement over the level of social capital.

The resulting model demonstrated the influence of social capital of front/back office on knowledge transfer in NSD. The main conclusions are as follows: the level of common cognition and trust relation both have a significantly positive influence on knowledge transfer willingness; 
the level of tie strength has a significant influence on front/back office transfer opportunity. Transfer willingness has a significant positive influence on transfer effect, the level of knowledge sharing and transfer efficiency; transfer opportunity has a significant influence on the level of sharing and transfer efficiency, and transfer capability has a strong influence on the increase of enhanced knowledge, level of sharing and transfer efficiency.

\section{Contributions}

This paper describes solutions that are affected by the separation of front and back offices, which naturally exerts influence on the characteristics of knowledge transfer activities. According to Alexander and Martin's (2013) view on knowledge transfer activities in innovation networks, the relationship between the main parties plays an important role in knowledge transfer due to frequent interpersonal interactions. Therefore, in NSD, both the structural and relational social capitals have significant influence on knowledge transfer. Some companies have reaped little benefit in actual practice because they neglected to insure the construction of relational social capital. This resulted in an unwillingness to contribute knowledge, making the infrastructure nothing but a flashy ornament.

This study also provides a preliminary explanation on the influence of social capital of front/back office on knowledge transfer in NSD and has proved the presence of the impact of organizational structure, culture and system on the characteristics and performance of knowledge transfer activities in NSD. This conforms to the view of the organizational system school and provides insight to avoid the marketing stereotype in which the interaction between an organization and its external environment is over-emphasized while the construction of the organization itself is overlooked. This study suggests that we should highlight the intra-organization factors such as the front/back office configuration so to smooth the process of NSD. Indeed, the front office has already grasped the customers' demand through daily interaction with them. Therefore, we should simply encourage the front and back offices to build social capital so to ensure the natural knowledge transfer.

\section{Implications}

When carrying out NSD, organizations with isolated front and back offices should construct the social capital of front/back office with a strategic prospective. Besides establishing more communication channels and platforms, emphasis should also be placed on the fostering of such relational social capital as trust and common cognition in/between front and back offices.

First, at the concept generation and development stages, the overall level of front office social capital should be elevated by constructing strong-tie networks such as the increase of contacts between front office staff and customers, partners, colleagues and peers; the relational trust and common cognition with customers and partners is especially stressed. This helps an organization to identify large potential market demand thus contributing to the development of new business products. Meanwhile, weak ties such as the communication and learning among colleagues and peers should also be established, as well as certain degree of trust and common cognition; this will increase the chances to obtain new service information from this source.

Second, in developing new business and process innovation projects, the barrier of isolated front/back office should be removed and strong ties between front and back offices should be formed through the establishment of project teams and a fixed job location; the level of trust and common cognition between front and back offices should be enhanced to ensure the integration of the expression and dissemination of tacit knowledge from both front and back offices and the promotion of efficiency in NSD based on customers' needs. 
Finally, at the introduction stage of NSD in banks, new service is usually introduced through various formal ways by the dissemination of explicit knowledge expressed through texts or information system; therefore, the construction of social capital in front/back office at this stage can be realized by establishing extensive weak ties to improve the popularity and efficiency when promoting the new service.

\section{Limitations}

This paper takes a holistic approach to study the influence mechanism of the front/back office social capital on knowledge transfer in NSD in regional banks. However, some variables in the structural dimension of front/back office social capital, such as network density, centrality of locations, and structural equivalence, may also exert influence on knowledge transfer. Future research can examine front/back office from a network perspective to further investigate these effects. Although we have conducted case screening and cross-group analysis aimed to obtain more comprehensive and detailed conclusions, the occurrence of subjective bias and omissions is still inevitable using a case study approach. Further empirical study is needed to test the theoretical framework and the propositions in this paper. This study found that there is a certain degree of causal relationship among the three dimensions of social capital. For example, trust relation (relation) and common cognition (cognition) can to some extent increase contact frequency (structure). This is discussed by Tsai and Ghoshal (1998). Also, there exist some connections among the three constructs of knowledge transfer effect. For instance, the increase in enhanced knowledge is dependent on the level of knowledge sharing. The analysis on the influence among these constructs cannot be realized through case study, so empirical study should be carried out by constructing models using structural equations modeling.

\section{Acknowledgement}

This work was supported by the Natural Science Foundation of China (Grant No. 70972136).

\section{References}

Aalbers, R., Dolfsma, W., \& Koppius, O. (2013). Individual connectedness in innovation networks: On the role of individual motivation. Research Policy, 42(3), 624-634.

Alexander, A. T., \& Martin, D. P. (2013). Intermediaries for open innovation: A competence-based comparison of knowledge transfer offices practices. Technological Forecasting and Social Change, 80(1), $38-49$.

Argote, L., \& Ingram, P. (2000). Knowledge transfer: A basis for competitive advantage in firms. Organizational Behavior and Human Decision-Processes, 82(1), 150-169.

Bakker, R. M., Cambr, B., Korlaar, L., \& Raab, J. (2011). Managing the project learning paradox: A settheoretic approach toward project knowledge transfer. International Journal of Project Management, 29(5), 494-503.

Berman, S., \& Heilweg, S. (1989). Perceived supervisor communication competence and supervisor satisfaction as a function of quality circle participation. The Journal of Business Communication, 26(1), 103-122.

Bian, Y. (1997). Bringing strong ties back in: Indirect ties, network bridges, and job searches in China. American Sociological Review, 62(3), 366-385.

Bou-Llusar, J. C., \& Segarra-Ciprés, M. (2006). Strategic knowledge transfer and its implications for competitive advantage: An integrative conceptual framework. Journal of Knowledge Management, 10(4), 100-112. 
Boyer, K. K., \& Lewis, M. W. (2002). Competitive priorities: Investigating the need for trade-offs in operations strategy. Production and Operations Management, 11(1), 9-20.

Cohen, W. M., \& Levinthal, D. A. (1998). Absorptive capacity: A new Perspective on learning and innovation. Administrative Science Quarterly, 35(1), 128-152.

Cummings, J. L., \& Teng, B.-S. (2003). Transferring R\&D knowledge: The key factors affecting knowledge transfer success. Engineering and Technology Management, 20(1), 39 -68.

Darr, E. D., Argote, L., \& Epple, D. (1995). The acquisition transfer and depreciation of knowledge in service organizations: Productivity in Franchises. Management Science, 41(11), 1750-1762.

Darr, E. D., \& Kurtxberg, T. R. (2000). An investigation of partner similarity dimensions on knowledge transfer. Organizational Behavior and Human Decision Processes, 82(1), 28-44.

Davenport, T. H., \& Prusak, L. (1998). Working knowledge: How organizations manage what they know. Boston: Harvard Business School Press.

de Silva, M., Huttly, S. R., Harpham, T., \& Kenward, M. G. (2006). Psychometric and cognitive validation of a social capital measurement tool in Peru and Vietnam. Social Science \& Medicine, 62(4), 941-953.

Eisenhardt, K.M. (1989). Building theories from case study research. Academy of Management Review, 14(4), 532-550.

Galbraith, C.S. (1990). Transferring core manufacturing technologies in high technology firms. California Management Review, 32(1), 56-70.

Gallouj, F., \& Weinstein, O. (1997). Innovation in services. Research Policy, 26(5), 537-556.

Ghobadi, S., \& D'Ambra, J. (2011). Coopetitive relationships in cross-functional software development teams: How to model and measure? Journal of Systems and Software, 85(5), 1096-1104.

Granovetter, M. S. (1973). The strength of weak ties. American Journal of Sociology, 78(6), 1360-1380.

Gupta, A. K., \& Govindarajan, V. (2000). Knowledge flow within multinational corporation. Strategic Management Journal, 21(4), 473-496.

Hammami, H., Amara, N., \& Landry, R. (2013). Organizational climate and its influence on brokers' knowledge transfer activities: A structural equation modeling. International Journal of Information Management, 33(1), 105-118.

Hansen, M. T. (1999). The search-transfer problem: The role of weak ties in sharing knowledge across organization sub-units. Administrative Science Quarterly, 44(1), 82-111.

Krogh, G. V., \& Roos, J. (1996). Managing knowledge: Perspectives on cooperation and competition. London: SAGE Publications.

Harpham, T., Grant, E., \& Thomas, E. (2002). Measuring social capital within health surveys: Key issues. Health Policy and Planning, 17(1), 106-111.

Johne, A. (1996). Avoiding product development failure is not enough. European Management Journal,14(2),176-180.

Johne, A., \& Storey, C. (1998). New service development: A review of the literature and annotated bibliography. European Journal of Marketing, 32(3), 184-251.

Johnston, R., \& Clark, G. (2001). Service operations management. Harlow: Pearson Education.

Karlsen, J., \& Gottschalk, P. (2004). Factors affecting knowledge transfer in IT projects. Engineering Management Journal, 16(1), 3-10.

Ke, J., \& Shi, J. (2007). Optimizing the structure of social capital for effective knowledge transfer in knowledge team. $R \& D$ Management, 19(1), 21-27 (in Chinese).

Kim, S., Suh, E., \& Jun, Y. (2011). Building a knowledge brokering system using social network analysis: A case study of the Korean financial industry. Expert Systems with Applications, 38(12), 14633-14649. 
Kim, Y., Lee, Z., \& Gosain, S. (2005). Impediments to successful ERP implementation process. Business Process Management Journal, 11(2), 158-170.

Kostova, T. (1999). Transnational transfer of strategic organizational practices: A contextual perspective. Academy of Management Review, 30(1), 8-32.

Larsson, R., \& Bowen, D.E. (1989). Organization and customer: Managing design and coordination of services. Academy of Management Review, 14(1), 35-48.

Leana, C. R., \& van Buren, H. J. (1999). Organizational social capital and employment practices. Academy of Management Review, 24(3), 538-555.

Li, Z., \& Zhu, T. (2009). Empirical study on the influence of social capital to informal knowledge transfer among individuals. Science of Science and S\&T Management, 30(9), 77-84 (in Chinese).

Lin, N. (2002). Social capital: A theory of social structure and action. Cambridge: Cambridge University Press.

Lochner, K. A., Kawachi, I., \& Kennedy, B. P. (1999). Social capital: A guide to its measurement. Health \& Place, 5, 259-270.

Lovelock, C. (1984). Developing and implementing new services. In W. R. George\& C. E. Marshall (Eds.), Developing new services (pp. 44-64). Chicago: American Marketing Association.

Lu, Y. (2007). Source and measurement of social capital. Seeker, 5, 5-8 (in Chinese).

Ma, J., Zhong, W., \& Chen, Y. (2007). An analysis of factors affecting knowledge transfer cost based on knowledge transfer context. Journal of Beijing Technology and Business University (Social Science), 22(3), 102-107 (in Chinese).

Metters, R., \& Vargas, V. (2000). A typology of de-coupling strategies in mixed services. Journal of Operations Management, 18(6), 663-682.

Menor, L. J., \& Roth, A. V. (2008). New service development competence and performance: An empirical investigation in retail banking. Production and Operations Management, 17(3), 267-284.

Miles, I., Kastrinos, N., Flanagan, K., Bilderbeek, R., den Hertog, P., Huntink, W., \& Bouman, M. (1995). Knowledge-intensive business services: Their roles as users, carriers and sources of innovation, Luxembourg.

Nahapiet, J., \& Ghoshal, S. (1998). Social capital, intellectual capital and the organizational advantage. Academy of Management Review, 23(2), 242-266.

Nelson, K. M., \& Cooprider, J. G. (1996). The contribution of shared knowledge to IS group performances. MIS Quarterly, 20(4), 409-429.

Nonaka, I., \& Takeuchi, H. (1995). The knowledge creating firm. New York: Oxford University Press.

O’Dell, C., \& Grayson, C. J. (1998). If only we knew what we know: Identification and transfer of internal best practices. California Management Review, 44(3), 154-174.

Park, B. (2011). Knowledge transfer capacity of multinational enterprises and technology acquisition in international joint ventures. International Business Review, 20(1), 75-87.

Reagans, R., \& McEvily, B. (2003). Network structure and knowledge transfer: The effects of cohesion and range. Administrative Science Quarterly, 48(2), 240-267.

Safizadeh, M. H., Field, J. M., \& Ritzman, L. P. (2003). An empirical analysis of financial services processes with a front-office or back-office orientation. Journal of Operations Management, 21(5), 557576.

Sarin, S., \& Mcdermott, C. (2003). The effect of team leader characteristics on learning, knowledge application, and performance of cross-functional new product development teams. Decision Sciences, 34(4), 707-739. 
Shu, L. (2007). Empirical analysis on influence factors of knowledge transfer within R\&D unit under technological innovation perspective. Science of Science and S\&T Management, 28(7), 108-114 (in Chinese).

Szulanski, G. (1996). Exploring internal stickiness: Impediments to the transfer of best practice within the firm. Strategic Management Journal, 17(1), 27-43.

Tang, Y., \& Shi, J. (2006). A synthesis of abroad study on knowledge transfer. Information Science, 24(1), 153-160 (in Chinese).

Tao, Y., Wei, J., \& Wang, T. (2007). Analysis of knowledge transfer in financial service innovation process. Journal of Dalian University of Technology (Social Science), 28(1), 11-16 (in Chinese).

Tsai, W. (2002). Social structure of competition within a multiunit organization: Coordination, competition and intra-organizational knowledge sharing. Organization Science, 13(2), 179-190.

Tsai, W., \& Ghoshal, S. (1998). Social capital and value creation: The role of intra-firm networks. Academy of Management Journal, 41(4), 464-476.

van Wijk, R., Jansen, J. J. P., \& Lyles, M. A. (2008). Inter- and intra-organizational knowledge transfer: A meta-analytic review and assessment of its antecedents and consequences. Journal of Management Studies, 45(4), 830-853.

Voss, C. (1992). Measurement of innovation and design performance in services. Design Management Journal, 3(1), 40-46.

Yan, A., \& Gray B. (1994). Bargaining power, management control, and performance in US-China joint ventures: A comparative case study. Academy of Management Journal, 37(6), 1478-1517.

Yao, Z., Hu, M., \& Ye, M. (2012). The impact of social network on small loan application: The case study of Zhejiang Tailong Bank. The Proceedings of China Case Study Forum, Beijing, 1-21 (in Chinese).

Yi, F. (2006). Core compete oriented knowledge transfer and innovation. Beijing: China Economy Press (in Chinese).

Yin, R. K. (2003). Case study research: Design and methods (3rd ed.). Thousand Oaks, CA: Sage Publications.

Zhang, G., Liu, S., \& Shen, H. (2011). Organizational structure, knowledge transfer channel and R\&D team innovation performance: An hi-tech enterprise-based empirical study. Studies in Science of Science, 29(8), 1198-1206 (in Chinese).

Zhang, R., \& Yu, B. (2008). A study of influencing factors on effectiveness of knowledge transfer within technology alliances. Studies in Science of Science, 26(5), 1024-1030 (in Chinese).

Zhu, S. (2010). The influence path of social capital to knowledge transfer within team. Unpublished Master dissertation, East China Normal University (in Chinese). 


\section{Biographies}

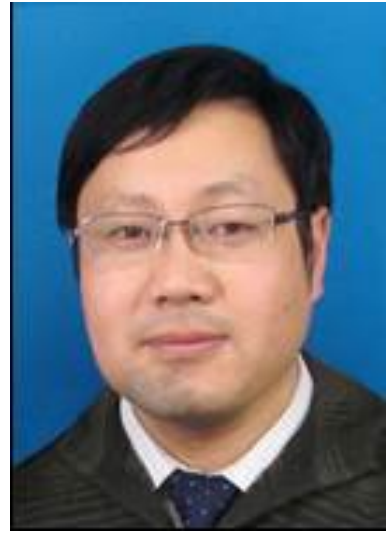

Jing-Hua Li Dr. (Bus. Adm.) is PhD Supervisor, Vice Director of Research Center for Technology Innovation and Service Management of Zhejiang Gongshang University. He obtained doctor degree from Southwest Jiaotong University of China in 2001. His research focuses on new service development and service innovation.

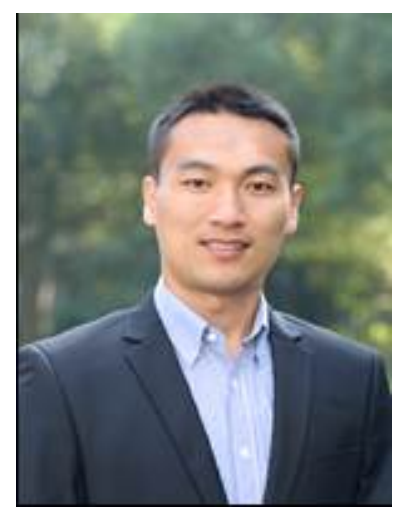

Qiu-Bo Huang M.Sc. (Bus. Adm.), PhD candidate in Research Centre for Technology Innovation and Service Management of Zhejiang Gongshang University. He is lecturer of Institute of Modern Services, Zhejiang Shuren University also. His research area is service innovation and management.

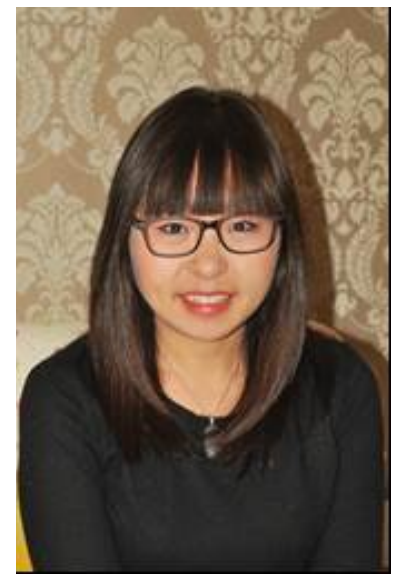

Li Lin, M.Sc. (Bus. Adm.), PhD student and lecturer in Research Centre for Technology Innovation and Service Management of Zhejiang Gongshang University. Her current researh focuses on service innovation and policy. 


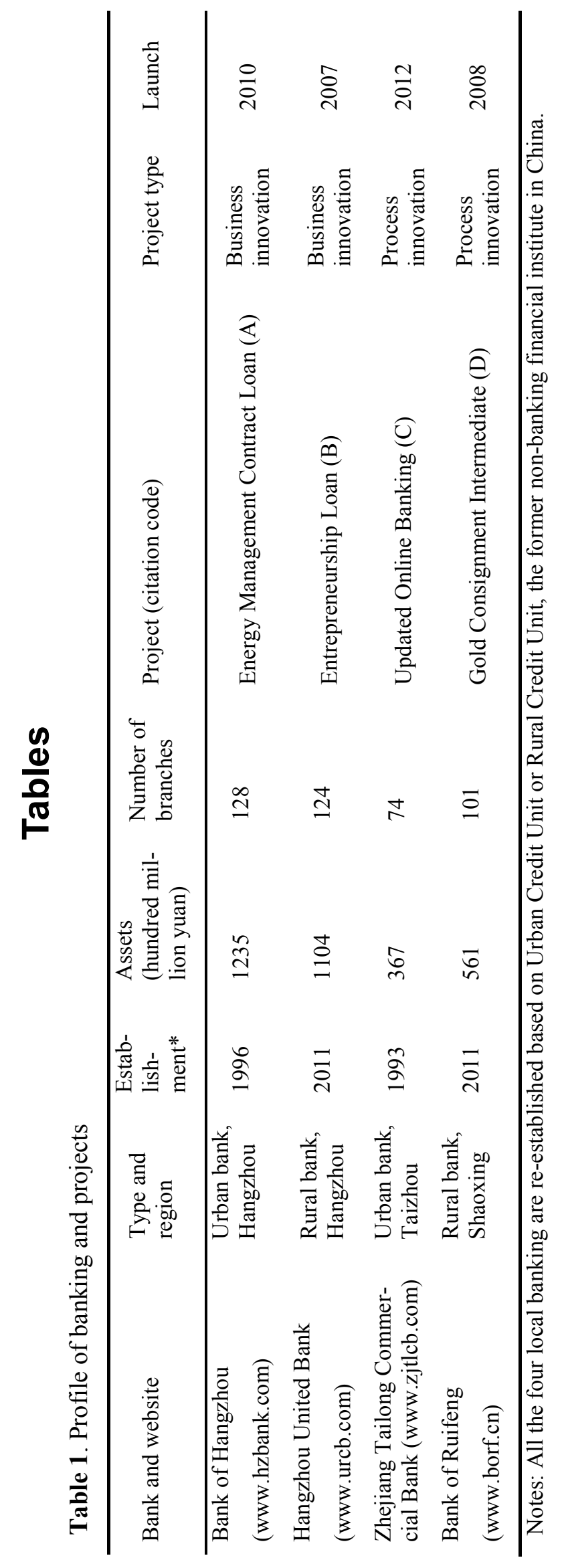




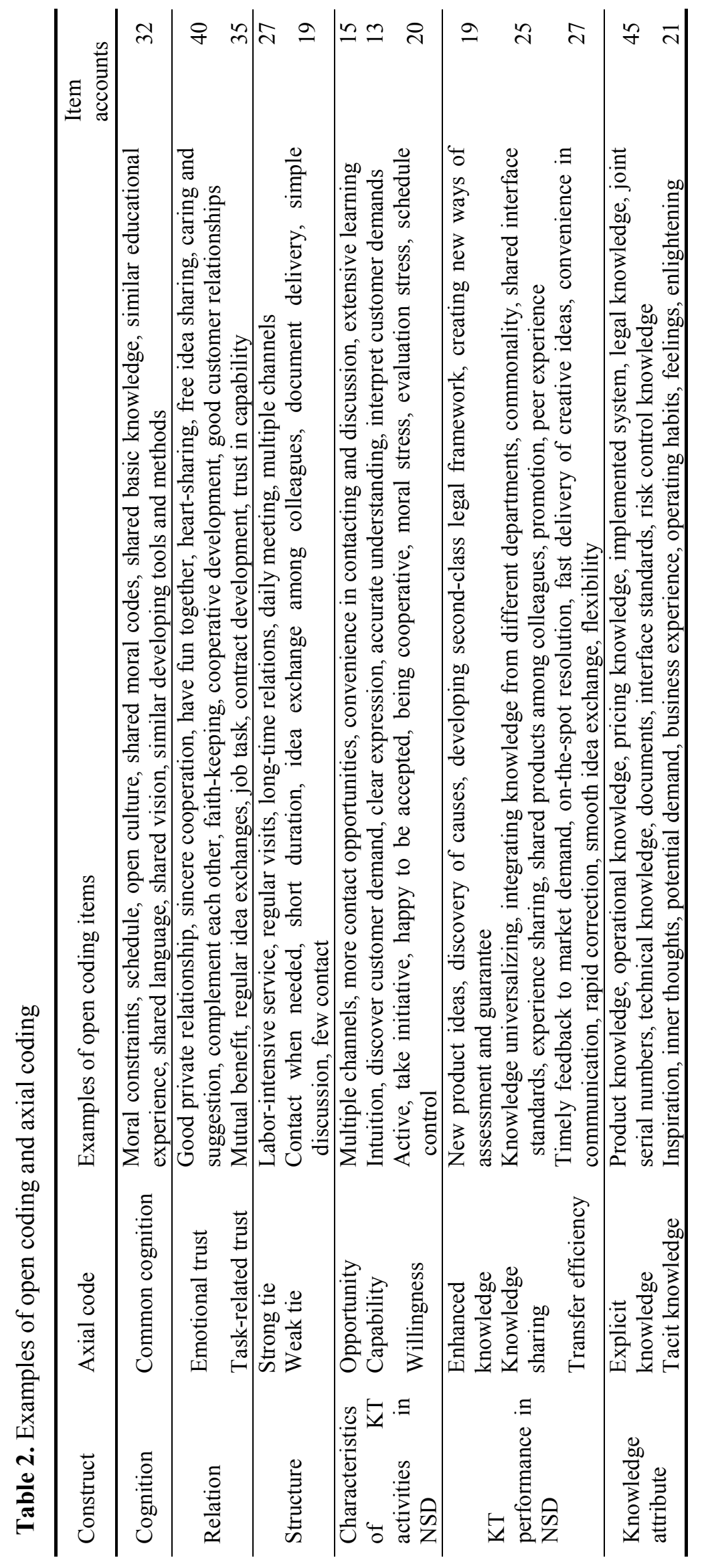




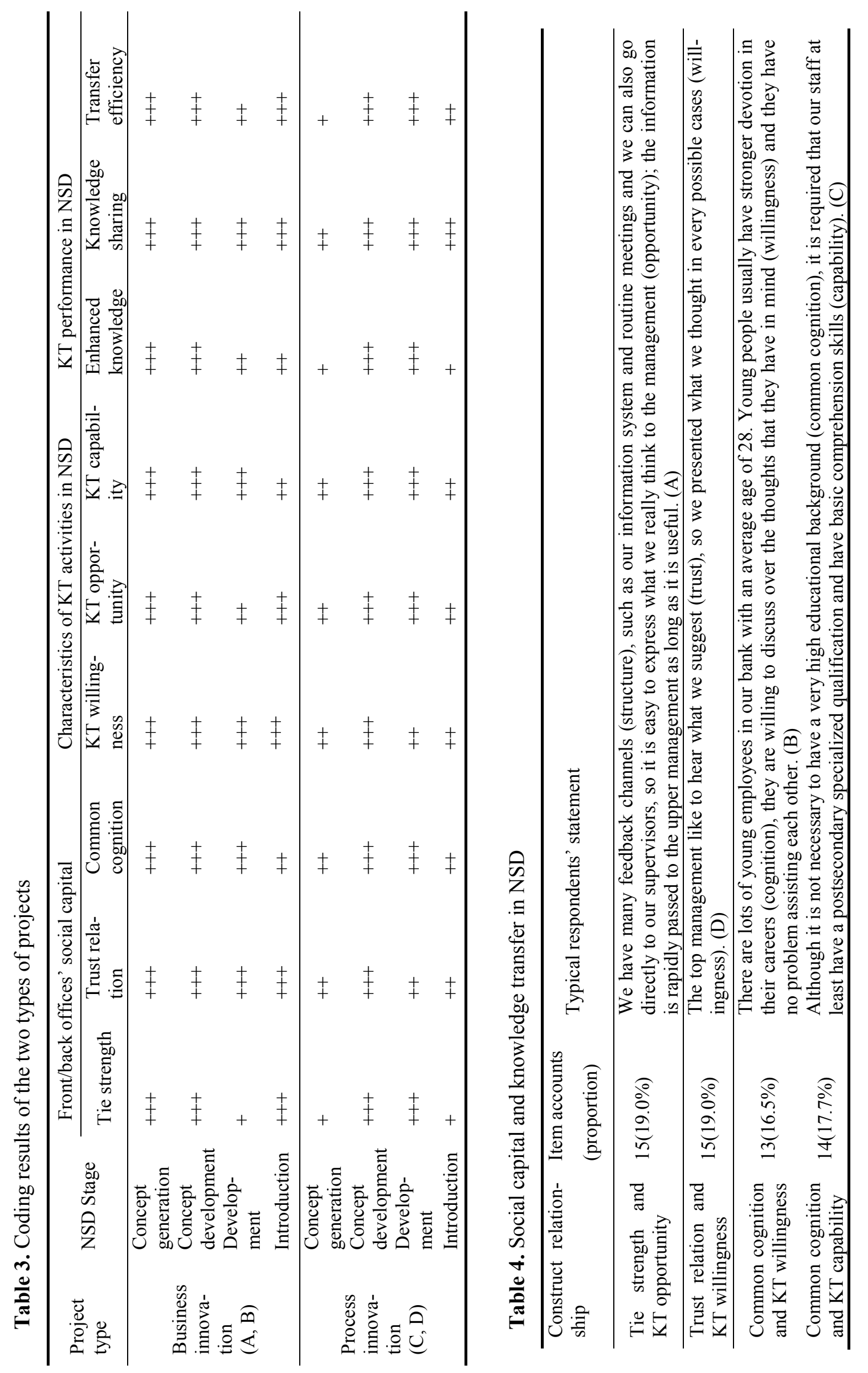




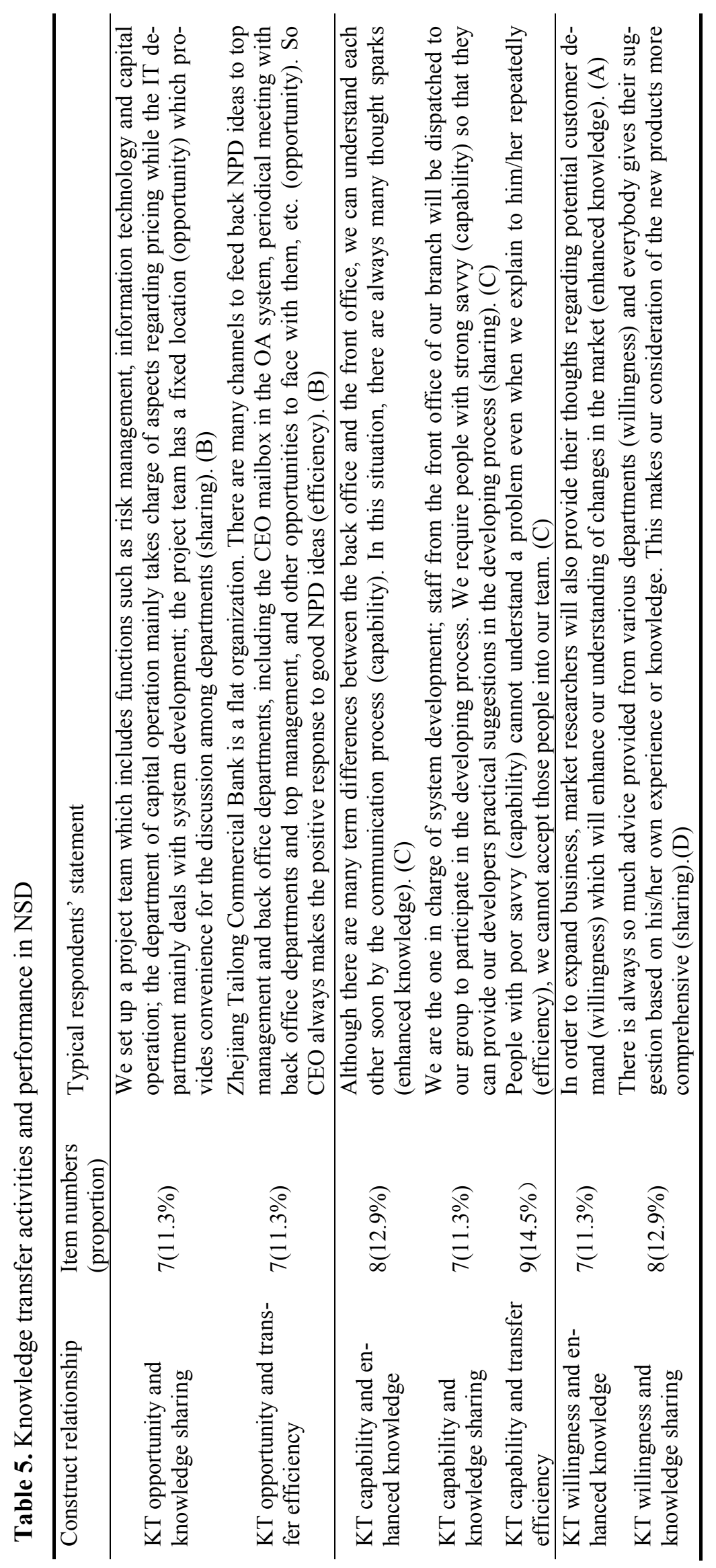

